\title{
Expressing Indifference: Spanish Un NP Cualquiera*
}

\author{
Luis Alonso-Ovalle \\ McGill University
}

\author{
Paula Menéndez-Benito \\ University of Göttingen
}

\begin{abstract}
Across languages, we find indefinites that trigger modal inferences. Some of these indefinites, like Spanish un NP cualquiera or the Korean -na indeterminates (Choi 2007) convey indifference on the part of an agent. In this paper, we assess whether a number of proposals on the market can be extended to account for the indifference component of un NP cualquiera.
\end{abstract}

Keywords: Modal Indefinites, Indifference, Free Choice, Spanish

\section{Introduction}

Across languages, we find indefinites that trigger modal inferences in non-modal contexts. Some of these 'modal indefinites,' like Spanish algún or German irgendein, convey information about the speaker's epistemic state (Kratzer \& Shimoyama (2002), Alonso-Ovalle \& Menéndez-Benito (2010), among others.) Algún, for instance, marks ignorance on the part of the speaker: (1) conveys that the speaker is unable to identify the book that Juan took. Other modal indefinites, like Spanish un $N P$ cualquiera, the Korean -na indeterminates, the French $n$ 'importe qu-indefinites, or German irgendein, can convey indifference on the part of an agent (Kratzer \& Shimoyama 2002; Zabbal 2004; Kim \& Kaufmann 2007; Choi 2007; Choi \& Romero 2008). The sentence in (2), for instance, can signal that Juan took a book randomly.

(1) Juan cogió algún libro.

Juan took ALGÚN book

'Juan took some book — I don't know which one.'

(2) Juan cogió un libro cualquiera.

Juan grabbed a book CUALQUIERA

'Juan took a random book.'

* We are very grateful to the audience of SALT 21 for extremely helpful discussions. Many thanks also to the members of the McGill Syntax-Semantics Research Group, especially Brian Buccola, Heather Burnett, Brendan Gillon, Bernhard Schwarz, Junko Shimoyama, and Walter Pedersen, for useful comments and insightful suggestions. Of course, all errors are our own.

C2011 Luis Alonso-Ovalle and Paula Menéndez-Benito 
There is by now a substantial body of research on indefinites that convey speaker's ignorance or knowledge. ${ }^{1}$ In contrast, agent indifference implications have not received as much attention on the literature. ${ }^{2}$ The present work is part of a long-term project that aims to investigate agent indifference implications crosslinguistically. Our goal in this paper is quite modest: we will focus on Spanish un NP cualquiera and assess whether a number of proposals on the market can be extended to account for its behavior.

The paper is organized as follows. Section 2 briefly describes the interpretation of un NP cualquiera. Section 3 discusses a counterfactual account of the agent indifference component (Choi 2007), section 4, an extension of the analysis of German irgendein presented in Kratzer \& Shimoyama 2002, and section 5, an analysis in the spirit of Zabbal (2004). Section 6 sums up the discussion. We conclude that the first two accounts make wrong predictions when applied to un $N P$ cualquiera. Adopting the Zabbal-style account would require us to motivate further some pieces of the analysis, and would leave open a question regarding the interpretation of of un NP cualquiera in modal contexts. Even though this discussion is not conclusive, we hope that the issues it raises will ultimately pave the way towards an analysis of un NP cualquiera.

\section{Un NP Cualquiera}

Morphologically, the DP un NP cualquiera consists of the indefinite determiner un and an NP that contains the free choice item cualquiera (3a), which doubles up as a determiner $(3 \mathrm{~b})$. It is possible to replace the indefinite with a plural numeral, as illustrated in $(3 a){ }^{3}$
a. [DP un (\{dos, tres ... $\})$ [NP libro(s) [cualquiera $]]$
b. [DP cualquier [NP libro]]

Sentences with un NP cualquiera make an existential claim. For instance, (2) conveys that Juan took a book. Additionally, they can trigger an agent indifference effect: (2) can convey that Juan chose the book randomly. We will refer to this reading as the 'agent indifference reading.' The sentence in (2) can also signal that the book that Juan took was not a special or remarkable one. This reading is compatible with Juan having selected the book carefully, as long as the speaker

1 See, e.g., references quoted in Alonso-Ovalle \& Menéndez-Benito 2010.

2 Some notable exceptions are Choi 2007, Kim \& Kaufmann 2007, Choi \& Romero 2008, and Zabbal 2004, which is unpublished.

3 The determiner cualquiera has different properties from un NP cualquiera. For instance, it is ruled out in episodic sentences. For a discussion of this item, which we will ignore in the rest of the paper, the reader is referred to Quer 2000, Menéndez-Benito 2005, and Menéndez-Benito 2010. 
believes that the outcome is not remarkable. From now on, we will ignore this 'unremarkable reading' and concentrate on the agent indifference reading. ${ }^{4}$

In what follows, we will assess whether some proposals on the market can be extended to capture the agent indifference reading of un NP cualquiera. We start with the analysis of Korean -na indeterminates presented in Choi 2007.

\section{The Counterfactual Approach (Choi 2007)}

Choi (2007) shows that Korean -na indeterminates have an indifference component. The example in (4), for instance, conveys that John picked a card and that he did so randomly. Building on von Fintel (2000), Choi claims that this indifference component comes about via a counterfactual presupposition. In what follows, we will first present Choi's account and then discuss whether it can successfully account for the behavior of un NP cualquiera. ${ }^{5}$

$$
\begin{aligned}
& \text { John-un amwu-khadu-na cip-ess-e. } \\
& \text { John-TOP AMWU-card-OR take-PAST-DEC } \\
& \text { 'John took just any old card.' }
\end{aligned}
$$

(Choi 2007: 204)

\subsection{Choi (2007)}

Choi's proposal is modeled after von Fintel's account of English -ever free relatives, which also have an indifference reading (von Fintel 2000; Tredinnick 2005; Rawlins 2008). The example in (5), for instance, indicates that Zach indiscriminately voted for the person that was at the top of the ballot.

(5) Zach simply voted for whoever was at the top of the ballot.

(von Fintel 2000: 32)

According to von Fintel, the indifference component can be given a counterfactual paraphrase: on this view, (5) conveys (i) that Zach voted for the person who

4 Sometimes, the 'unremarkable' interpretation corresponds to what Haspelmath (1997) calls a depreciative reading. However, this is not always the case. The sentence in (i), for instance, simply says that yesterday was a normal day in Juan's life, and does not convey a negative attitude on the part of the speaker.

(i) Ayer fue un día cualquiera en la plácida vida de Juan. yesterday was a day CUALQUIERA in the placid life of Juan 'Yesterday, it was a normal day in the placid life of Juan.'

5 Kim \& Kaufmann (2007) present a different account of the Korean -na indeterminates. We will not review it here. 
was at the top of the ballot and (ii) that if the person at the top of the ballot had been a different one, Zach would have voted for that person just the same. On von Fintel's analysis, (i) corresponds to the assertion of the sentence and (ii) is derived via a presupposition. This is spelled out in (6), which assumes a minimal change semantics for counterfactuals (Lewis 1973). ${ }^{6}$

a. Assertion: Zach voted for the individual at the top of the ballot in $w_{0}$.

b. Presupposition: all the worlds $w^{\prime}$ in which the individual at the top of the ballot is not the actual individual at the top of the ballot and that otherwise differ minimally from $w_{0}$ are such that Zach voted for the individual at the top of the ballot in $w^{\prime}$ iff he voted for the actual individual at the top of the ballot in $w_{0}$.

Choi extends von Fintel's analysis to the Korean -na indefinites. On her proposal, these indefinites contribute an existential claim at the assertion level and trigger a presupposition that makes reference to counterfactual scenarios. The example in (4), for instance, asserts that John took a card and presupposes that in all worlds where the set of cards is different from the actual set of cards (but that are otherwise maximally similar to the actual world) John takes a card if and only if he took a card in the actual world. If the assertion is true, the presupposition can only be satisfied if John takes a card in all the (maximally similar) worlds where the set of cards differs from the actual set of cards. This condition does not impose indifference on the part of the agent just by itself, but it will be satisfied in a world in which John does not have a preference as to which card to take, and where, consequently, he would have taken a card regardless of what cards were available.

The analysis is implemented as in (7) below, where the indefinite takes as arguments a world of evaluation, a set of worlds $F$ (a modal base), and two properties $P$ and $Q$. The function $\min$ in the metalanguage takes a world $w$ and a proposition $p$ and returns the worlds in which $p$ is true that are maximally similar to $w$. Similarity here is determined with respect to the properties of $w$ : for any worlds $w^{\prime}$ and $w^{\prime \prime}, w^{\prime \prime}$ is at least as close to $w$ as $w^{\prime}$ iff the set of propositions that are true in both $w$ and $w^{\prime \prime}$ is a subset of the set of propositions that are true in both $w$ and $w^{\prime}$.

6 It should be mentioned that von Fintel himself casts doubt on the presuppositional status of the indifference component. In cases like (ii), for instance, the counterfactual component does not project out of the unless clause, contrary to what we would expect if it were a presupposition.

(ii) Unless Zack simply voted for whoever was at the top of the ballot, he must have spent at least five minutes in the voting.

(von Fintel 2000: 36) 
Expressing Indifference: Spanish Un NP Cualquiera

a. LF: wh-/amwu-(N)-na $\left(w_{0}\right)(F)(P)(Q)$

b. Presupposition:

$$
\begin{aligned}
& \forall w^{\prime} \in \min _{w_{0}}\left[F \cap\left(\lambda w^{\prime \prime} .\left[\begin{array}{c}
\left\{x: P_{w^{\prime \prime}}(x)\right\} \\
\neq \\
\left\{x: P_{w_{0}}(x)\right\}
\end{array}\right]\right)\right] \begin{array}{r}
\exists x\left[P_{w^{\prime}}(x) \wedge Q_{w^{\prime}}(x)\right] \\
= \\
\exists x\left[P_{w_{0}}(x) \wedge Q_{w_{0}}(x)\right]
\end{array} \\
& \text { c. Assertion: } \exists x\left[P_{w_{0}}(x) \wedge Q_{w_{0}}(x)\right] \\
& \text { (Choi 2007: 114) }
\end{aligned}
$$

Choi \& Romero (2008) suggest that this type of account extends to un NP cualquiera. In what follows, we will show that the counterfactual component above does not property characterize the indifference component of this item.

\subsection{Issue 1: Free Choice Constrains the Type of Accessibility Relation}

According to Choi, the indifference component of -na indefinites can be characterized as a free choice effect: (4) conveys that, as far as John's preferences go, he could have taken any card. The same applies to un NP cualquiera on its agent indifference reading. Consider the scenarios in (8-9), adapted from von Fintel (2000). The sentence in (10) is perfectly fine in (9), but it is inappropriate in (8). We contend that this is so because (10) conveys that Zach voted for a candidate and that, as far as he was concerned, he could have voted for any of the three candidates.

(8) When Zach went to vote last Saturday, he had three choices: Barack Obama, John McCain, and Ralph Nader. He did not want to vote for McCain, but he had no preference with respect to the other two, so he simply chose one of the two arbitrarily.

(9) Same as above, except that Zack did not care who he voted for, so he chose one of the three candidates arbitrarily.

(10) Zach votó por un candidato cualquiera.

Zach voted for un candidate CUALQUIERA

'Zach voted for a random candidate.'

Following Menéndez-Benito (2005), Choi paraphrases the free choice component of (4) as 'for any card $x$, there is an accessible world where John took only $x$.' That is, assuming that the only cards under consideration are the Jack, the Queen, and the King of Hearts, (4) requires the three conditions in (11) to be satisfied.

(11) a. There is an accessible world where Juan took only the Jack of Hearts.

b. There is an accessible world where Juan took only the Queen of Hearts.

c. There is an accessible world where Juan took only the King of Hearts. 
Choi notes that for her account to derive this free choice effect, we must make sure that for each individual $d$ in the extension of the NP, the set of accessible worlds that is being quantified over includes worlds where the extension of the NP is a singleton set containing only $d$ (Choi 2007: 202 and ff.). To see why, let us suppose again that the only cards under consideration are the Jack, the Queen, and the King of Hearts. Now assume that the domain of quantification contains only the worlds in (12). Suppose, furthermore, that John takes the Jack of Hearts in the worlds in W1 and W2, and the King of Hearts in the worlds in W3. Assume also that Juan took one of these cards in the actual world. Given the proposal in (7), (13) below is predicted to be true and felicitous in this scenario: the assertion is true (Juan took a card), and the presupposition is satisfied: Juan took a card in each of the worlds in the domain of quantification. Intuitively, however, (13) cannot describe the scenario above. The sentence conveys that Juan could have taken any card, but there is no accessible world in which John takes the Queen of Hearts.

$$
\begin{aligned}
& W 1=\min _{w_{0}}\left(\left\{w \mid \llbracket \text { carta } \rrbracket^{w}=\{J \triangleright, Q \triangleright\}\right\}\right) \\
& W 2=\min _{w_{0}}\left(\left\{w \mid \llbracket \operatorname{carta} \rrbracket^{w}=\{\overline{Q \triangleright}, \underline{K \triangleright}\}\right\}\right) \\
& W 3=\min _{w_{0}}\left(\left\{w \mid \llbracket \text { carta } \rrbracket^{w}=\{\underline{J \varnothing}, \overline{K \triangleright}\}\right\}\right) \\
& \text { (13) Juan cogió una carta cualquiera. } \\
& \text { Juan grabbed a card CUALQUIERA } \\
& \text { 'Juan took a random card.' }
\end{aligned}
$$

Given this, Choi argues that we need the domain of quantification to contain the worlds in (14) (which we will dub the 'singleton worlds'). If these worlds are among the accessible ones, then, if the assertion is true, we can conclude that Juan would have taken any card.

$$
\begin{aligned}
& W 1=\min _{w_{0}}\left(\left\{w \mid \llbracket \text { carta } \rrbracket^{w}=\{J \odot\}\right)\right. \\
& W 2=\min _{w_{0}}\left(\left\{w \mid \llbracket \text { carta } \rrbracket^{w}=\{Q \odot\}\right)\right. \\
& W 3=\min _{w_{0}}\left(\left\{w \mid \llbracket \text { carta } \rrbracket^{w}=\{K \odot\}\right)\right.
\end{aligned}
$$

The assumption that the domain of quantification must contain these 'singleton worlds' is not unproblematic, though. For the domain of quantification to contain these worlds, we would have to assume that they are as close to the actual world (where there are three cards) as those worlds where there are two cards. We think, however, that we do not need to make that assumption when we interpret (13). To make the problem more dramatic, consider (15). Suppose Juan is an astronomer who took a picture of a random planet. The sentence can felicitously describe that event even in a context where we assume that the worlds where there is only one planet are more remote from the actual world than those where there is, say, only one planet less than in our universe. 
Expressing Indifference: Spanish Un NP Cualquiera

Juan fotografió un planeta cualquiera.

Juan photographed a planet CUALQUIERA

'Juan took a picture of a random planet.'

The next section shows that forcing the kind of accessibility relation above is not enough. If we include the 'singleton worlds' in our domain of quantification, Choi's account will make wrong predictions for some examples.

\subsection{Issue 2: Wrong Predictions}

Consider the following scenario:

(16) Juan is a gambler. He needs to pick a card. He will choose randomly, but wants to make sure first that the deck is complete. For that, he carries around a machine that flashes a green light whenever the deck has exactly fifty-two cards. The machine flashed a green light and Juan picked a random card.

Intuitively, (13) is true and felicitous in the scenario above. However, Choi's counterfactual presupposition fails to be satisfied in this context, so the sentence is predicted to be deviant. To see why, assume that similarity is measured with respect to the following propositions, all of which are true in the actual world.

$p_{1}$ : that there are fifty-two cards in the deck.

$p_{2}$ : that Juan takes a card if and only if there are fifty-two cards in the deck.

$p_{3}$ : that Juan takes a card.

The presupposition requires all the closest worlds where the extension of carta is different from the one at the actual world to be worlds where Juan takes a card (since he actually took a card). As we saw in the previous section, to capture the free choice effect we must include in the domain of quantification worlds where there is only one card. Let us now consider the worlds where there is only one card that satisfy as many propositions in (17) as possible. In all worlds where there is only one card, $p_{1}$ is false. Given that, $p_{2}$ and $p_{3}$ cannot be both true in those worlds (in worlds where there are less than fifty-two cards, for $p_{2}$ to be true, $p_{3}$ has to be false.) We then need to consider those worlds in which there is only one card and either $p_{2}$ or $p_{3}$ is true, as illustrated in (18). The counterfactual presupposition requires Juan to take a card in the two types of worlds in (18). Yet, in our scenario, Juan only takes a card in the Type 2 worlds. The presupposition, then, is not satisfied in this context.

\begin{tabular}{|c|cc|}
\hline & W1 & W2 \\
\hline$p_{2}$ : Juan takes a card $\leftrightarrow$ there are 52 cards & T & F \\
$p_{3}$ : Juan takes a card & F & T \\
\hline
\end{tabular}


We conclude, then, that the type of counterfactual component that Choi assumes does not properly characterize the indifference component of un NP cualquiera. In the next section, we try a different way of deriving this component.

\section{Extending Kratzer and Shimoyama (2002)}

Kratzer \& Shimoyama (2002) show that German irgendein triggers a free choice effect in connection with modals, and argue that this effect arises through the interaction of the modal operator and the domain constraints imposed by irgendein. They further suggest that the ignorance effect conveyed by irgendein in non-modal sentences could in principle be captured in the same way by assuming that these sentences contain a covert assertoric operator. This suggestion was taken up in later work (Alonso-Ovalle \& Menéndez-Benito 2003; Chierchia 2006; Alonso-Ovalle \& Menéndez-Benito 2010). In what follows, we will explore and ultimately reject a similar account, on which the modal component of un NP cualquiera also arises via the interaction with a covert modal.

\subsection{Background: Kratzer and Shimoyama 2002}

Kratzer \& Shimoyama (2002) argue that irgendein conveys a free choice effect when in the scope of a modal operator. For instance, on the narrow scope reading of the indefinite, the sentence in (19) indicates that Mary was allowed to marry any doctor in the domain of quantification.

(19) Mary darf irgendeinen Arzt heiraten.

Mary can IRGENDEIN doctor marry

'Mary can marry any doctor.'

(A minimal variation on an example in Kratzer \& Shimoyama (2002: 28))

Kratzer \& Shimoyama (2002) derive this free choice effect as a conversational implicature that arises because irgendein is a domain widener. On this view, while a plain indefinite like ein selects a contextually salient set of doctors, irgendein selects all the doctors in the world of evaluation. Following Kadmon \& Landman (1993), Kratzer \& Shimoyama (2002) assume that domain wideners are only used when there is a reason to do so. One of the reasons they consider is avoidance of a false exhaustivity inference. To see what this means, consider the dialogue below.

a. A: Which doctor is Mary allowed to marry?

b. B: She's allowed to Mary Dr. Abad or Dr. Báez.

Assume that the doctors under consideration are Dr. Abad, Dr. Báez and Dr. Cabal. Since B's claim ranges over a domain that does not contain Dr. Cabal, A 
will conclude that Mary is not allowed to marry this doctor. According to Kratzer \& Shimoyama (2002), the sentence in (19) conveys that there is at least one permitted world where Mary marries at least one of the doctors $(\diamond(A \vee B \vee C))^{7}$. Considering the widest domain possible blocks potential exhaustivity inferences. The hearer will compare the assertion with all the stronger assertions that result from restricting the domain $(\diamond(\mathrm{A} \vee \mathrm{B}), \diamond(\mathrm{B} \vee \mathrm{C}), \diamond(\mathrm{A} \vee \mathrm{C}), \diamond \mathrm{A}, \diamond \mathrm{B}, \diamond \mathrm{C})$ and conclude that none of them is true while the others are false. Since the asertion entails that at least one of the competitors is true, the assertion together with the inference entails that all of them are. This yields the free choice effect, namely that Mary is allowed to marry Dr. Abad and Dr. Báez, and Dr. Cabal.

\subsection{Extension: Covert Modality}

As noted above, Kratzer and Shimoyama's proposal has been extended to deal with ignorance effects in sentences where there is no overt modal (Alonso-Ovalle \& Menéndez-Benito 2003; Chierchia 2006; Alonso-Ovalle \& Menéndez-Benito 2010). According to Alonso-Ovalle \& Menéndez-Benito (2010), the ignorance effect that algún displays in sentences like (21) arises through the interaction of a domain constraint imposed by the indefinite and a covert assertoric operator that quantifies over the doxastic alternatives of the speaker.

\section{(21) Juan cogió algún libro.}

Juan took ALGÚN book

'Juan took some book — I don't know which one.'

This raises the question of whether the agent indifference reading triggered by $u n$ $N P$ cualquiera can be captured in a similar fashion. This would amount to assuming that (i) un NP cualquiera is a domain widener, and (ii) that sentences with un NP cualquiera contain a covert modal, related to the preferences of the agent. On this view, the sentence in (22) would have the LF in (23). ${ }^{8}$

Juan cogió una carta cualquiera.

Juan took a card CUALQUIERA

'Juan took a random card.'

7 Notation: 'A' stands for the proposition that Mary married Dr. Abad, 'B' for the proposition that Mary married Dr. Báez, and ' $\mathrm{C}$ ' for the proposition that she married Dr. Cabal.

8 The hypothesis that (22) contains a covert goal-oriented modal may not be too far-fetched a possibility. Some other constructions, like the relative infinitival in (iii) below, can convey goal-oriented modality in the absence of an overt modal (Bhatt 2006).

(iii) The man to fix the sink is here. ( $\approx$ The man whose purpose is to fix the sink is here.)

(Bhatt 2006: 9) 
In what follows, we will explore a proposal along the lines above, and ultimately conclude that this type of account cannot successfully capture the indifference effect triggered by un NP cualquiera.

\subsection{Issue 1: The Indifference Component is not an Implicature}

Kratzer \& Shimoyama (2002) derive the free choice effect of irgendein as an implicature. This is supported by the fact that the free choice effect disappears in downward entailing contexts, just like quantity-based implicatures. For instance, by uttering (24) I convey that I doubt that she was allowed to invite anybody at all (and not that I doubt whether she was allowed to invited anybody she wanted.)

Ich bezweifle, dass sie je irgendjemand einladen durfte.

I doubt that she ever irgend-one invite could

'I doubt that she was ever allowed to invite anybody.'

(Kratzer \& Shimoyama 2002: 14)

In contrast, the indifference effect of un NP cualquiera does not disappear in downward entailing contexts: the sentence in (25a) conveys that Juan took a book and that his choice was not indiscriminate, and it cannot be read as saying that Juan didn't take any book at all. Similarly, (25b) means that the speaker has doubts about whether Juan picked indiscriminately (and not that the speaker has doubts as to whether Juan picked any book at all). ${ }^{9}$ This contrasts sharply with the ignorance effect triggered by algún, which disappears in downward entailing contexts (Alonso-Ovalle \& Menéndez-Benito 2010).

a. Juan no cogió un libro cualquiera.

Juan not took a book CUALQUIERA

'Juan did not take a random book.'

b. Dudo que Juan haya cogido un libro cualquiera. doubt that Juan has taken a book CUALQUIERA

'I doubt that Juan has taken a random book.'

The behavior of the indifference component of un NP cualquiera in downward entailing environments casts serious doubts on its implicature status. Normally, implicatures can only be retained in downward entaling contexts with the help of focus operators or emphatic stress. For instance, Kratzer and Shimoyama provide

9 Zabbal (2004) makes the same observation regarding the free choice effect displayed by n'importe qu indefinites. 
the example in (26), where stressed irgendein preceded by einfach nur maintains its free choice component in a downward entailing environment.

(26) Sie darf nie einfach nur IRGENDjemand einladen. she may never just only irgend-one invite

'She is never allowed to invite just ANYbody.'

(Kratzer \& Shimoyama 2002: 14)

In the case of un NP cualquiera, however, the indifference effect is always kept under downward entailing operators, without any focus operators or special stress patterns. To make this compatible with the claim that the indifference effect is an implicature, we would have to find a reason why this effect is more robust than implicatures usually are. We do not know what this reason could be. In any event, we will show in the next section that, even if we were able to come up with such a reason, we would still not be able to maintain the proposal under consideration. As we will see, this account wrongly predicts that (22) should convey that Juan took all the cards in the domain.

\subsection{Issue 2: Too Many Actuality Entailments.}

The proposal that we are considering assumes that a sentence like (22), repeated below as (27), has the LF in (28), and, that, therefore, it makes a modal assertion.

Juan cogió una carta cualquiera.

Juan took a card CUALQUIERA

'Juan took a random card.'

LF: $\left[\emptyset_{\text {Modal }}\left[[\right.\right.$ a card $]\left[1\left[\right.\right.$ Juan [took $\left.\left.\left.\left.\left.\mathrm{t}_{1}\right]\right]\right]\right]\right]$

To be able to assess the predictions of this hypothesis, we will need to first characterize the covert modal that we are positing. Intuitively, the agent-indifference effect of a sentence like (27) conveys that as far as Juan was concerned, all the cards were equally good alternatives. This suggests that the modal in (28) is evaluated with respect to a circumstantial modal base and an ordering source related to the agent's preferences. On this view, the agent's indifference effect of (27) corresponds to the condition in (29). ${ }^{10}$

(29) For every $\operatorname{card} x$, there is a world $w^{\prime}$ where the relevant circumstances in $w$ are true and that satisfies Juan's preferences in $w$ as well as possible, given the circumstances, and where Juan takes $x$.

10 This is a simplification. As noted above, to capture the free choice effect, we would need to say that for each card $x$, there is a world where Juan took $x$ and only $x$ (see Menéndez-Benito 2005, 2010). In what follows, we will ignore this component. 
What can the modal force of the covert modal be? Assuming that it is a necessity modal would predict truth-conditions that are too strong. Consider, for instance, the sentence in (30). This sentence can felicitously describe the scenario in (31). However, if (30) contained a covert necessity modal (with the modal base and ordering source specified above) we would expect this sentence to be inappropriate in (31): it is not true that in all the worlds where the relevant circumstances obtain and that are best with respect to what Juan wants, he bought a book - the worlds where Juan buys a book satisfy Juan's preferences just as well as the worlds where Juan buys a cd or a scarf. Assuming that (30) is a possibility statement, in contrast, does not run into this problem. It is true in (31) that, given the circumstances, and what he wants, Juan could buy a book.

(30) Juan compró un libro cualquiera.

Juan bought a book CUALQUIERA

'Juan bought a random book.'

(31) Juan needed to buy a birthday present for María. He considered buying a book, a cd, or a scarf. Any of these presents would be fine with him. Furthermore, any book, any cd, or any scarf would do for him. He ended up going into a bookstore and buying the first book that he saw.

But the truth-conditions that we predict now are too weak. After all, the sentence in (30) entails that Juan did buy a book. This, however, is not necessarily a problem. The covert modal that we are positing is a root modal, and it is well known that root modals yield actuality entailments in combination with perfective aspect (Bhatt 2006; Hacquard 2009, 2006). For instance, the example in (32), where the possibility modal poder bears perfective aspect, entails that Juan ate chocolate cake.

(32) Juan pudo comer tarta de chocolate.

Juan could:PFV eat:INF cake of chocolate

'Juan could eat chocolate cake.'

Hacquard (2006) argues that actuality entailments arise whenever perfective aspect scopes over the modal. In her system, the sentence in (32) would have the syntactic structure in (33). Her semantics assigns to (33) the truth conditions in (34): that there is an actual past event that is an event of eating chocolate cake by John in at least one accessible world. To guarantee that the actual event described by (34) is an event of eating chocolate cake by John in the actual world, Hacquard assumes the principle in $(35)^{11}$.

$11^{\prime}$ ' $\tau$ ' is a function that maps any event $e$ to its running time, ' $t$ ' picks up a contextually salient time interval. 
(33) LF: [past [perfective [ Poss [Juan eat that chocolate cake]]]]

$\exists e\left[e \in w_{0} \& \tau(e) \subseteq t \& \operatorname{past}(t) \& \exists_{w^{\prime}}\left[\operatorname{eat}_{w^{\prime}}(e, j, c)\right]\right]$

Preservation of Event Description Across Worlds:

for all $\mathrm{w}_{1}, \mathrm{w}_{2}$, if $\mathrm{e}_{1}$ occurs in $\mathrm{w}_{1}$ and in $\mathrm{w}_{2}$ and $\mathrm{e}_{1}$ is a P-event in $\mathrm{w}_{1}$, then ceteris paribus, $\mathrm{e}_{1}$ is a $\mathrm{P}$-event in $\mathrm{w}_{2}$ as well.

(Hacquard 2006, 2009)

In our example (27), the verb bears perfective morphology. If we assume that perfective aspect scopes over the covert modal, as in (36), Hacquard's system will yield the truth-conditions in (37), which, given the Preservation of Event Description Across Worlds Principle, would entail that Juan took a card at some point in the past.

$$
\begin{aligned}
& \text { LF: [past [perfective [ } \emptyset_{\text {Mod }}\left[\text { [a card] } 1 \text { Juan [ took } \mathrm{t}_{1}\right] \text { ]]]] } \\
& \exists e\left[e \in w_{0} \& \tau(e) \subseteq t \& \operatorname{past}(t) \& \exists_{w^{\prime}} \exists x\left[\operatorname{card}_{w_{0}}(x) \& \operatorname{take}_{w^{\prime}}(e, j, x)\right]\right]
\end{aligned}
$$

Let us take stock: in order to derive the indifference effect triggered by un NP cualquiera via Kratzer and Shimoyama's account we need to assume that sentences with un NP cualquiera contain a covert modal. And to derive the right truth conditions for these sentences we need this modal to trigger an actuality entailment (which, assuming Hacquard's account, amounts to saying that we need to assume the syntactic structure in (36)). Unfortunately, when we combine these assumptions with the pragmatic reasoning put forward by Kratzer \& Shimoyama (2002), we automatically derive a number of unattested actuality entailments. Let us see why.

Consider again the proposition in (37), corresponding to the sentence in (27). Recall that the pragmatic competitors of the assertion are alternative propositions that differ from the assertion only in that the indefinite ranges over a proper subset of the maximal domain. Let us assume again that the only cards under consideration are the Jack, the Queen, and the King of Hearts. The pragmatic competitors of (37) above will then be the propositions expressed by the formulae that the schema below determines, where $\mathscr{D}$ is a metavariable ranging over the non empty proper subsets of the set containing the Jack, the Queen, and the King of Hearts.

$$
\exists e\left[e \in w_{0} \& \tau(e) \subseteq t \& \operatorname{past}(t) \& \exists_{w^{\prime}} \exists x\left[x \in \mathscr{D} \& \operatorname{take}_{w^{\prime}}(e, j, x)\right]\right]
$$

The pragmatic reasoning spelled out in section 4.1 yields the implicature that all these competitors are true. Given Hacquard's principle in (35), this entails, contrary to fact, that there is an actual event of Juan taking the Jack, an actual event of Juan taking the Queen, and an actual event of him taking the King. ${ }^{12}$

12 Aloni \& van Rooij (2007) first noted that Kratzer and Shimoyama's antiexhaustivity reasoning predicts that indefinites like irgendein should convey universal quantification in non-modal, episodic contexts. Here we see that the problem also arises when we have a modal that triggers actuality entailments. 


\section{Importing the Free Choice Effect into the Semantics}

In section 4.3 we saw that the indifference effect induced by un NP cualquiera does not behave like a run-of-the-mill implicature. The interaction of the indifference effect with negation shows that this effect is not a presupposition or a conventional implicature - in the sense of Potts (2005) - either. First, while presuppositions project past negation, the indifference component cannot do so. The example in (39) is not felicitous in a context where it is taken for granted that all the books are equally good options as far as Juan is concerned. Second, conventional implicatures cannot be targeted by negation, unlike the indifference component ((39) conveys that Juan was choosy). All this leads to the conclusion that the indifference component is truth conditional. In this section, we will discuss an account that hardwires the indifference effect into the semantics of un NP cualquiera.

(39) Juan no cogió un libro cualquiera.

Juan not take a book CUALQUIERA

'Juan didn't take a random book.'

\subsection{A Zabbal-style analysis for Un NP Cualquiera}

The analysis that we present in this section is essentially Zabbal's account of n'importe qu- indefinites, with one difference: while Zabbal contends that n'importe $q u$ - must combine with a modal, we will assume that un NP cualquiera introduces the modal component itself. ${ }^{13}$

Zabbal adopts the Hamblin semantics for indefinites put forward in Kratzer \& Shimoyama (2002). In this framework, expressions of type $\tau$ are mapped to sets of denotations in $D_{\tau}$. Indefinite NPs denote sets of individual alternatives, as in (40a). Other items denote singleton sets that contain their standard denotations (40b). Functional Application is defined pointwise, as in Hamblin (1973): the result of combining an expression $\alpha$ denoting a set of functions of type $\langle\sigma, \tau\rangle$ with an expression $\beta$ denoting a set of objects of type $\sigma$ is the set of objects of type $\tau$ that we get by applying each of the functions denoted by $\alpha$ to each of the objects denoted by $\beta$. Given this, the individual alternatives introduced by indefinites into the semantic derivation give rise to alternatives of a higher type via pointwise functional application. The combination of the indefinite in (40a) with the verb in (40b), for instance, gives us the set of propositions in (40c).

13 Jayez \& Tovena (2005) also put forward an account for the semantics of $n$ ' importe qu-indefinites. However, they focus on modal contexts. They argue that the use of $n$ 'importe qu- in modal contexts crucially differs from its use in episodic sentences, where it receives an agent indifference interpretation. As this paper is concerned with the agent indifference reading, we will not discuss Jayez and Tovena's proposal. 
Expressing Indifference: Spanish Un NP Cualquiera
a. $\llbracket \mathrm{a} \operatorname{man} \rrbracket^{w}=\left\{x \mid \operatorname{man}_{w}(x)\right\}$
b. $\llbracket \operatorname{arrived} \rrbracket^{w}=\left\{\lambda x \lambda w^{\prime}\right.$ arrived $\left._{w^{\prime}}(x)\right\}$
c. $\llbracket \operatorname{arrived} \rrbracket^{w}\left(\llbracket \operatorname{a} \operatorname{man} \rrbracket^{w}\right)=\left\{p_{\langle s, t\rangle} \mid \exists x\left[\operatorname{man}_{w}(x) \& p=\lambda w^{\prime} \cdot \operatorname{arrived}_{w^{\prime}}(x)\right]\right\}$

Alternatives keep expanding until they meet one of several operators that take sets of propositional alternatives as arguments. The denotation of the sentence in (41), for example, is the result of combining the set of propositions in (40c) with the Existential Closure operator in (42): the (singleton containing the) proposition that at least one man arrived.

(41) A man arrived.

(42) For any set of propositions $\mathbb{A}: \llbracket[\exists] \rrbracket^{w, g}(\mathbb{A})=\left\{\lambda w^{\prime} . \exists p \in \mathbb{A} \& p\left(w^{\prime}\right)\right\}$

Working within this framework, Zabbal decomposes n' importe qu-into n'importe and $q u$-, and proposes that (i) $q u$ - is interpreted in situ as a Hamblin indefinite, while (ii) $n$ 'importe is interpreted as a propositional operator that conveys the free choice effect. Since n'importe operates over a set of propositions, it cannot be interpreted in its surface position. Zabbal assumes that it moves and adjoins to the IP node. Following this proposal, we will assume that the sentence in (43a) has the LF in (43b). In (43b), the indefinite una carta introduces a set of individual alternatives (43c), which 'grow' propositional via pointwise functional application. Cualquiera operates over the resulting set of propositional alternatives (43d) by (i) closing the set existentially and (ii) requiring each alternative to be true in some accessible world (43e). The LF in (43b) will then denote a proposition that is true in a world $w$ if and only if Juan took a card in $w$, and for each card $x$, there is an accessible world $w^{\prime}$ where Juan took $x$. Assuming that the accessible worlds are those where the relevant circumstances are true and that are best with respect to the preferences of the agent, this corresponds to the agent's indifference component. ${ }^{14,15}$

14 It is unclear to us how this LF is generated. It could be, as Zabbal assumes, the result of moving cualquiera. If so, we would need to think about how the trace of cualquiera is interpreted. It is also conceivable that the LF in (43b) is not derived via movement. Perhaps cualquiera signals the existence of a covert propositional operator, which ranges over the propositions in (43d). As important as this issue is, we will have to leave it open for now.

15 The interaction of un NP cualquiera with negation shows that cualquiera must scope below sentential negation. Assume to the contrary that (39) could get the LF below:

(iv) LF: cualquiera [ no [ Juan cogió un libro]]

Let us assume that no corresponds to Kratzer and Shimoyama's propositional quantifier, i.e., that it takes a set of propositions $\mathbb{A}$ and returns the (singleton containing the) proposition that is true in a world $w$ iff all members of $\mathbb{A}$ are false in $w$. Given this, (iv) would convey that Juan did not take a book and that not taking a book was compatible with his preferences. This is not a possible meaning for (39). One possible way of blocking the LF above would be to assume that cualquiera can only 

a. Juan cogió una carta cualquiera.
Juan took a card CUALQUIERA
b. LF: cualquiera [Juan cogió una carta]
c. $\llbracket$ una carta $\rrbracket^{w}=\{J \vee, Q \triangleright, K \triangleright\}$
d. $\llbracket J u a n$ cogió una carta $\rrbracket^{w}=$
$\left\{\lambda w \cdot \operatorname{took}_{w}(j, J \nabla), \lambda w \cdot \operatorname{took}_{w}(j, Q \nabla), \lambda w \cdot \operatorname{took}_{w}(j, K \oslash)\right\}$
e. $\llbracket$ cualquiera $\rrbracket^{w}(\mathbb{A})=\lambda w \cdot \exists p \in \mathbb{A}\left[p(w) \& \forall p \in \mathbb{A} \exists w^{\prime} \in A c c_{w}\left[p\left(w^{\prime}\right)\right]\right]$

This proposal hardwires the modal component of un NP cualquiera into its truthconditions. In the next section, we will see that the account faces some challenges when we consider sentences that contain negation or overt modals.

\subsection{Two Challenges}

The first challenge that we would like to discuss concerns the status of the existential component. According to the proposal presented in section 5.1, (44) can have the LF in (45). The proposition expressed by (45) should be true in a situation where Juan did not take any card. However, this prediction is not borne out. The sentence in (44) is only appropriate if Juan took a card (but not randomly). This is a problem that the proposal presented in section 5.1 shares with the other accounts that we have discussed, which also treat the existential claim as truth conditional. ((Choi 2007: 187) notes the issue.) The fact that the existential claim persists under negation suggests that it is a presupposition, rather than part of the assertion. In fact, the existential component seems to project out of some 'holes' (Karttunen (1973)): (46), for instance, sounds odd in a context where it is not taken for granted that Juan took a card. The issue is more complex, though: While the sentence in (47b) presupposes that the addressee has talked to John before, showing that the presupposition induced by again projects out of the scope of the necessity modal, (47a) does not seem to trigger any presupposition. At this point, it is unclear to us how to deal with this pattern within the account that we are exploring.

(44) Juan no cogió una carta cualquiera.

Juan not took a card CUALQUIERA

'Juan did not take a random card.'

$\mathrm{LF}_{1}$ : no [ cualquiera [ Juan cogió una carta]]

¿Cogió Juan una carta cualquiera?

took Juan a card CUALQUIERA

operate over a set containing more than one alternative. This requirement would not be satisfied in (iv), as no returns a singleton set. 
Expressing Indifference: Spanish Un NP Cualquiera

'Did Juan take a random card?'

a. Tienes que casarte con una princesa cualquiera. have:2s that marry with UNA princess CUALQUIERA 'You have to marry a random princess.'

b. You have to talk to John again.

Another issue that we would like to discuss has to do with the interaction of un NP cualquiera and modal operators. The proposal in 5.1 predicts that when un $N P$ cualquiera is in the scope of a modal, we should detect two layers of modality. Necessity sentences like (47a) above bear this prediction out. The sentence in (47a) can have the LF in (48). As expected, this sentence conveys that the addressee is required to marry a princess and to be indifferent as to the choice of princess. Suppose that, in order to inherit the throne, the prince must marry a princess before he turns thirty. As the prince will turn thirty in a couple of months, he cannot be choosy: he may have to marry the first princess that is available. In this context, the king could felicitously use (47a) to remind the prince of his obligations. However, the king could not utter (47a) in a situation where the prince is required to marry a princess, but where he is allowed to be as picky as he wants. ${ }^{16}$

\section{LF: have to [ cualquiera [ you marry a princess ]]}

In cases like (49) below, however, the indifference component seems to dissapear. When understood as a permission imperative, (49) simply conveys that the speaker gives her addressee permission to pick any book.

¡Coge un libro cualquiera!

take a book CUALQUIERA

'Take any book!'

If permission imperatives correspond to possibility statements, it is perhaps not so surprising that the indifference component is diluted in these cases. Embedding the indifference component under a possibility modal should convey that the addressee is allowed to have preferences. This requirement is very easy to satisfy, and is certainly satisfied in a context where the addressee is allowed to pick any book. ${ }^{17}$ However, the account that we are exploring fails to predict the free choice effect that we observe in cases like (49). This sentence is expected to convey that the addressee is allowed to pick a book and is allowed to be indifferent as to the choice of book.

16 In this respect, un NP cualquiera contrasts with irgendein (see Kratzer \& Shimoyama (2002)).

17 We do not have space here to try to justify this assumption, especially in view of the many recent developments in the semantics of imperatives (for an overview, see, for instance, Portner (to appear).) 
This does not entail that the speaker gives the addressee permission to pick any book. ${ }^{18}$

\section{Conclusions}

We have discussed three possible ways of deriving the indifference component of $u n$ $N P$ cualquiera. First, we have seen that trying to capture the indifference component by considering alternatives to the actual extension of the NP (Choi 2007) leads to wrong truth conditions. Second, we have seen that Kratzer and Shimoyama's pragmatic reasoning would derive the agent indifference effect as a conversational implicature, which is at odds with the fact that this effect does not disappear in downward entailing contexts. Even if we were comfortable with assuming that the implicature is routinely imported into the truth conditions, we would predict an unattested universal meaning for un NP cualquiera (replicating a problem first noted by Aloni \& van Rooij (2007).)

Adopting the Zabbal-style analysis sketched in 5.1. would require us to carefully spell out and motivate some of its crucial assumptions, in particular the proposed decomposition of un cualquiera. Assuming that these assumptions can indeed be motivated, this type of account gets us closer to what we need. But it still leaves important questions open. In particular, we are left with the puzzle of why the indifference component disappears in permission sentences. This is an issue that we plan to address in future work.

\section{References}

Aloni, Maria \& Robert van Rooij. 2007. Free choice items and alternatives. In G. Bouma, I. Kraemer \& J.Zwarts (eds.), Proceedings of the KNAW Academy Colloquium: Cognitive Foundations of Interpretation, 5-26. Edita KNAW.

Alonso-Ovalle, Luis \& Paula Menéndez-Benito. 2003. Some epistemic indefinites. In Makoto Kadowaki \& Shigeto Kawahara (eds.), Proceedings of the North East Linguistic Society, 33, 1-12. Amherst, MA: GLSA.

Alonso-Ovalle, Luis \& Paula Menéndez-Benito. 2010. Modal indefinites. Natural Language Semantics 18(1). 1-31. doi:10.1007/s11050-009-9048-4.

Bhatt, Rajesh. 2006. Covert modality in non-finite contexts. Berlin: Mouton de Gruyter.

Chierchia, Gennaro. 2006. Broaden your views. Implicatures of domain widening and the 'logicality' of language. Linguistic Inquiry 37(4). 535-590.

18 One could perhaps argue that the addresse can infer that he can pick any book from the fact that the speaker allows him to be indifferent to the book. However, the free choice component of un NP cualquiera does not have the status of a cancellable inference. 
Expressing Indifference: Spanish Un NP Cualquiera

Choi, Jinyoung. 2007. Free choice and negative polarity: A compositional analysis of Korean polarity sensitive items: University of Pennsylvania dissertation.

Choi, Jinyoung \& Maribel Romero. 2008. Rescuing existential free choice items in episodic sentences. In O. Bonami \& P. Cabredo Hoffner (eds.), Empirical Issues in Syntax and Semantics 7, vol. 7, 77-98.

von Fintel, Kai. 2000. Whatever. In Brendan Jackson \& Tanya Matthews (eds.), SALT X, 27-40. Ithaca, NY: CLC Publications.

Hacquard, Valentine. 2006. Aspects of modality: MIT dissertation.

Hacquard, Valentine. 2009. On the interaction of aspect and modal auxiliaries. Linguistics and Philosophy 32. 279-315.

Hamblin, C. L. 1973. Questions in Montague English. Foundations of Language 10. 41-53.

Haspelmath, Martin. 1997. Indefinite pronouns. Oxford: Oxford University Press. Jayez, Jacques \& Lucia Tovena. 2005. Free-choiceness and non individuation. Linguistics and Philosophy 28(1). 1-71.

Kadmon, Nirit \& Fred Landman. 1993. Any. Linguistics and Philosophy (16). 353-422.

Karttunen, Lauri. 1973. Presuppositions of compound sentences. Linguistic Inquiry (47). 169-193.

Kim, Min-Joo \& Stefan Kaufmann. 2007. Domain restriction in freedom of choice: A view from Korean indet-na items. In Estela Puig-Waldmüller (ed.), Proceedings of Sinn und Bedeutung, 375-389. Barcelona: Universitat Pompeu Fabra.

Kratzer, Angelika \& Junko Shimoyama. 2002. Indeterminate pronouns: The view from Japanese. In Y. Otsu (ed.), Proceedings of the 3rd Tokyo Conference on Psycholinguistics, 1-25.

Lewis, David. 1973. Counterfactuals. Oxford: Blackwell.

Menéndez-Benito, Paula. 2005. The grammar of choice. Amherst, MA: GLSA. Ph. D. dissertation, University of Massachusetts Amherst.

Menéndez-Benito, Paula. 2010. On universal free choice items. Natural Language Semantics 14(1). 33-64.

Portner, Paul. to appear. Permission and choice. In Günther Grewendorf \& Thomas Ede Zimmermann (eds.), Discourse and grammar. From sentence types to lexical categories, Berlin: Mouton de Gruyter.

Potts, Christopher. 2005. The logic of conventional implicatures. Oxford: Oxford University Press.

Quer, Josep. 2000. Licensing free choice items in hostile environments: The role of aspect and mood. SKY Journal of Linguistics 13. 251-268.

Rawlins, Kyle. 2008. (Un)conditionals: An investigation in the syntax and semantics of conditional structures: University of California, Santa Cruz dissertation.

Tredinnick, Victoria Ann. 2005. On the semantics of free relatives with-ever: 
University of Pennsylvania dissertation.

Zabbal, Youri. 2004. A compositional semantics of the French expression n'importe. Ms. University of Massachusetts Amherst.

Luis Alonso-Ovalle

Department of Linguistics

Department of Languages, Literatures and Cultures McGill University

Avenue du Docteur Penfield 1085

Montréal, Québec, Canada H3A 1A7

luis.alonso-ovalle@mcgill.ca
Paula Menéndez-Benito

Seminar für Englische Philologie

University of Göttingen

Käte-Hamburger-Weg 3

37073 Göttingen, Germany

pmenend@gwdg.de 